\title{
Homolytic substitution at phosphorus for C-P bond formation in organic synthesis
}

\author{
Hideki Yorimitsu ${ }^{1,2}$
}

\section{Review}

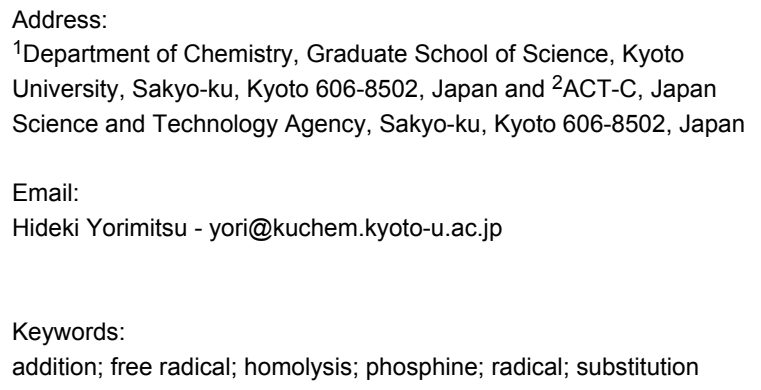

${ }^{1}$ Department of Chemistry, Graduate School of Science, Kyoto University, Sakyo-ku, Kyoto 606-8502, Japan and 2ACT-C, Japan Science and Technology Agency, Sakyo-ku, Kyoto 606-8502, Japan

(c) 2013 Yorimitsu; licensee Beilstein-Institut. License and terms: see end of document.

\begin{abstract}
Organophosphorus compounds are important in organic chemistry. This review article covers emerging, powerful synthetic approaches to organophosphorus compounds by homolytic substitution at phosphorus with a carbon-centered radical. Phosphination reagents include diphosphines, chalcogenophosphines and stannylphosphines, which bear a weak P-heteroatom bond for homolysis. This article deals with two transformations, radical phosphination by addition across unsaturated $\mathrm{C}-\mathrm{C}$ bonds and substitution of organic halides.
\end{abstract}

\section{Introduction}

Organophosphorus compounds constitute an important class of compounds in a wide range of applications in organic chemistry, as reagents, intermediates, ligands, bioactive agents, and functional materials [1-4]. The synthesis of organophosphorus compounds has therefore been extensively investigated (Scheme 1). Classical methods to form a $\mathrm{C}-\mathrm{P}$ bond include ionic reactions such as nucleophilic substitution of $\mathrm{P}-\mathrm{X}$ compounds with organometallic reagents, nucleophilic substitution of alkyl halides with phosphorus nucleophiles, and nucleophilic addition to polar unsaturated bonds. Recent advances in transition-metal catalysis have realized catalytic cross-coupling reactions of aryl halides with $\mathrm{H}-\mathrm{P}$ compounds [5-7] and catalytic addition to nonpolar unsaturated carbon-carbon bonds

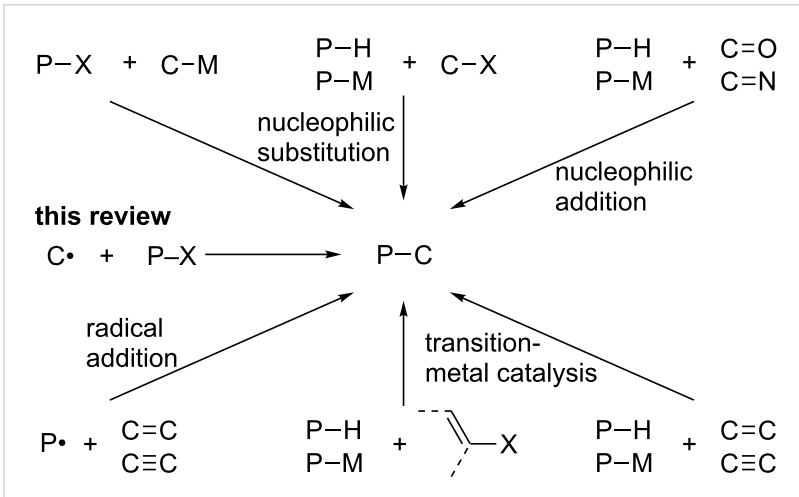

Scheme 1: Representative C-P bond-forming reactions. 
[8-11]. In the field of radical chemistry, the addition of phosphorus radicals, mainly from $\mathrm{H}-\mathrm{P}$ compounds, onto carbon-carbon multiple bonds [12-15] has held a special position since they provide transformations unattainable by polar reactions.

Homolytic substitution is a reaction in which a radical $(\mathrm{R} \bullet)$ attacks a saturated atom $(\mathrm{X})$ in a molecule with the liberation of a leaving radical $(\mathrm{L} \bullet)$ from the atom (Scheme 2). Homolytic substitution at halogen and chalcogen atoms is well known to proceed and hence has been widely used in organic synthesis [16-19]. In contrast, applications of homolytic substitution to $\mathrm{C}-\mathrm{P}$ bond formation have been rarely explored. With the growing importance of organophosphorus compounds, increasing attention has been paid to homolytic substitution at phosphorus. The new tool for C-P bond formation has achieved interesting transformations that ionic reactions cannot. This review summarizes homolytic substitution at phosphorus for $\mathrm{C}-\mathrm{P}$ bond formation in organic synthesis while the relevant mechanistic studies are found in the literature [19-21]. This review deals with two transformations, radical phosphination by addition across unsaturated $\mathrm{C}-\mathrm{C}$ bonds and substitution of organic halides.

$$
\mathrm{R} \cdot \underset{+}{\mathrm{X}}-\widehat{\mathrm{L}} \longrightarrow \mathrm{R}-\mathrm{X}+\mathrm{L} \cdot
$$

Scheme 2: General equation of homolytic substitution.

\section{Review}

\section{Radical addition of phosphination agents}

Stannylphosphines of the type $\mathrm{R}_{3} \mathrm{Sn}-\mathrm{PR}_{2}$ are known to undergo radical addition to carbon-carbon unsaturated bonds. Schumann reported the addition of diphenyl(triphenylstannyl)phosphine to allyl chloride, styrene, and phenylacetylene (Scheme 3) $[22,23]$. The addition is most likely to proceed via a radical process as the absence of AIBN leads to considerable decreases in yield. Mitchell then reported that diphenyl(trimethylstannyl)phosphine reacts not only with terminal alkynes but also with internal alkynes and allenes (Scheme 4) [24,25]. It is noteworthy that the regioselectivity of the radical addition to propynamide is opposite to that of the relevant ionic Michael addition. Considering the regioselectivity, these addition reactions naturally involve $\mathrm{C}-\mathrm{P}$ bond formation by homolytic substitution at phosphorus (Scheme 5). Studer recently reported similar silylphosphination of phenyl vinyl sulfone with $\mathrm{Me}_{3} \mathrm{Si}_{-}-\mathrm{PPh}_{2}$ [26].

Tzschach reported that tetraorganodiphosphines $\mathrm{R}_{2} \mathrm{P}-\mathrm{PR}_{2}$ add to phenylacetylene under UV irradiation or upon heating in the presence of AIBN (Scheme 6) [27]. The reaction consists of the

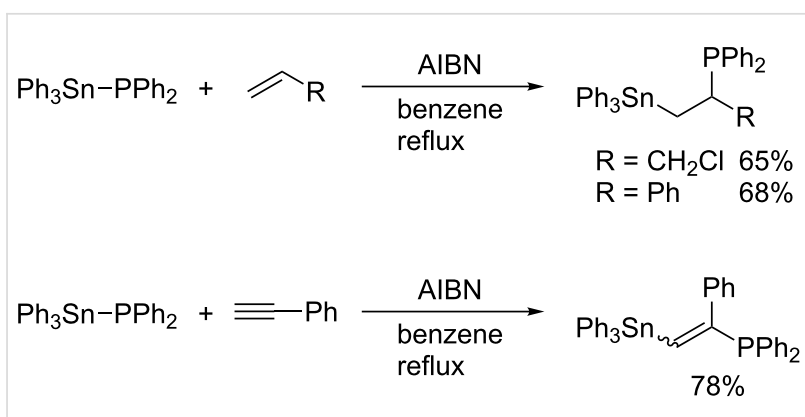

Scheme 3: Addition of diphenyl(triphenylstannyl)phosphine.

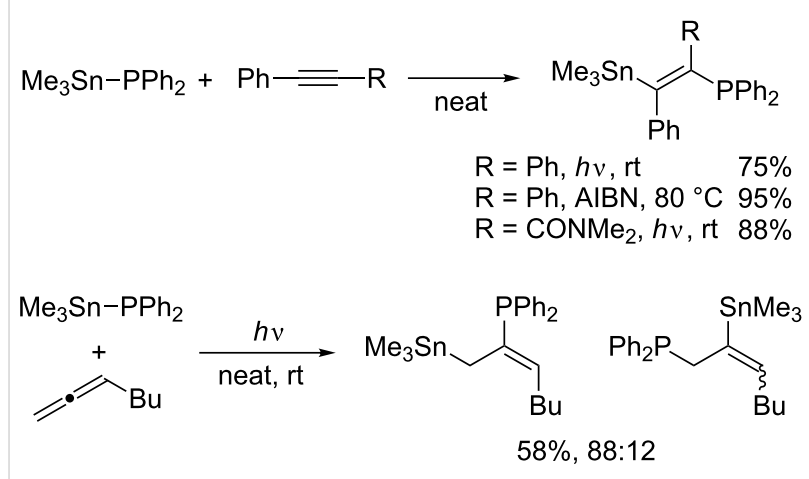

Scheme 4: Addition of diphenyl(trimethylstannyl)phosphine.

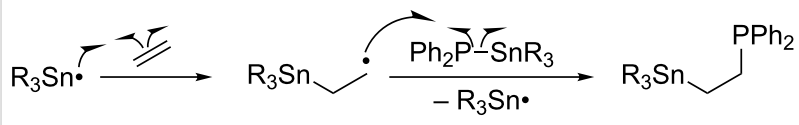

Scheme 5: Plausible mechanism of addition of $\mathrm{R}_{3} \mathrm{Sn}-\mathrm{PPh}_{2}$.

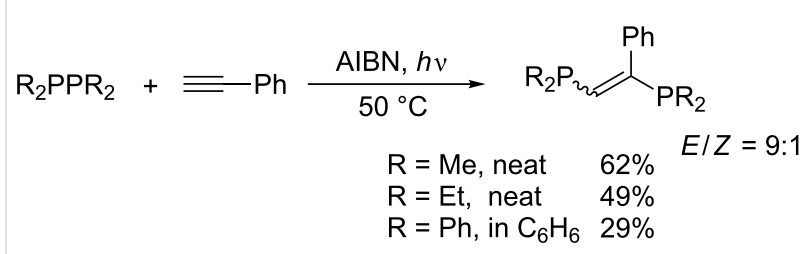

Scheme 6: Addition of tetraorganodiphosphines to phenylacetylene.

addition of a diorganophosphanyl radical to phenylacetylene and the homolytic substitution of tetraorganodiphosphine with the resulting vinyl radical to afford the adduct and to regenerate the initial diorganophosphanyl radical (Scheme 7). The high $E$ selectivity is attributable to kinetic control of the homolytic substitution, where $\mathrm{R}_{2} \mathrm{P}-\mathrm{PR}_{2}$ preferentially approaches the vinyl radical from the roomier side. Although the transformation looks useful to construct an (E)-1,2-diphosphanylethene skeleton, the scope of alkyne is limited to phenylacetylene and 


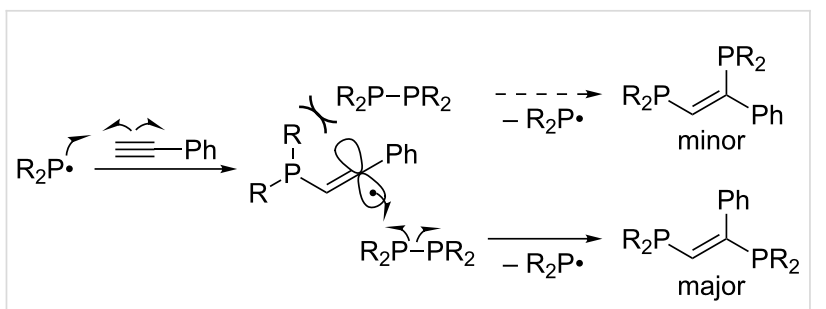

Scheme 7: Plausible mechanism of anti-diphosphination.

the reactions result in unsatisfactory yields because of the instability of the products as well as the diphosphines in air.

A more general, facile, and reliable method for diphosphination was later reported by Yorimitsu and Oshima, which utilizes diphosphines generated in situ from chlorophosphine and hydrophosphine in the presence of triethylamine [28]. A variety of terminal alkynes undergo the radical diphosphination (Table 1). The diphosphination was applicable to the synthesis of a new push-pull-type molecule that emits blue fluorescence (Scheme 8). The initially formed diphosphanylethylene derivatives are not very stable in air, and therefore sulfidation or oxidation was performed to accurately assess the efficiency of the diphosphination reactions.

Ogawa independently reported similar diphosphination under UV irradiation (Table 2) [29,30]. The reactions favor the formation of $Z$ isomers, which results from photoinduced isomeriza-

Table 1: Radical anti-selective diphosphination of terminal alkynes.

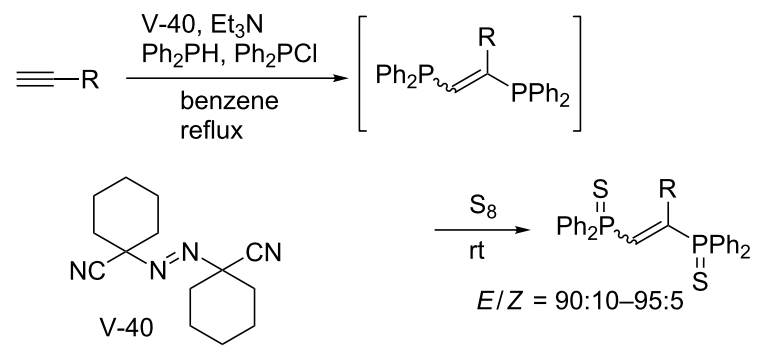

\begin{tabular}{ll}
\hline $\mathrm{R}$ & Yield (\%) \\
\hline $\mathrm{C}_{10} \mathrm{H}_{21}$ & 84 \\
$\mathrm{Ph}$ & 87 \\
$\mathrm{C}_{6} \mathrm{H}_{4}-p-\mathrm{OMe}$ & 89 \\
$\mathrm{C}_{6} \mathrm{H}_{4}-p-\mathrm{CO}_{2} \mathrm{Me}$ & 95 \\
$\mathrm{C}_{6} \mathrm{H}_{4}-p-\mathrm{I}$ & 83 \\
$\mathrm{C}_{6} \mathrm{H}_{4}-p-\mathrm{COMe}$ & 96 \\
$\left(\mathrm{CH}_{2}\right)_{3} \mathrm{OBn}$ & 78 \\
$\left(\mathrm{CH}_{2}\right)_{6} \mathrm{CO} \mathrm{CH}_{2} \mathrm{Et}$ & 86 \\
$\left(\mathrm{CH}_{2}\right)_{9} \mathrm{SCOMe}$ & 80 \\
$\left(\mathrm{CH}_{2}\right)_{9} \mathrm{Cl}$ & 86
\end{tabular}

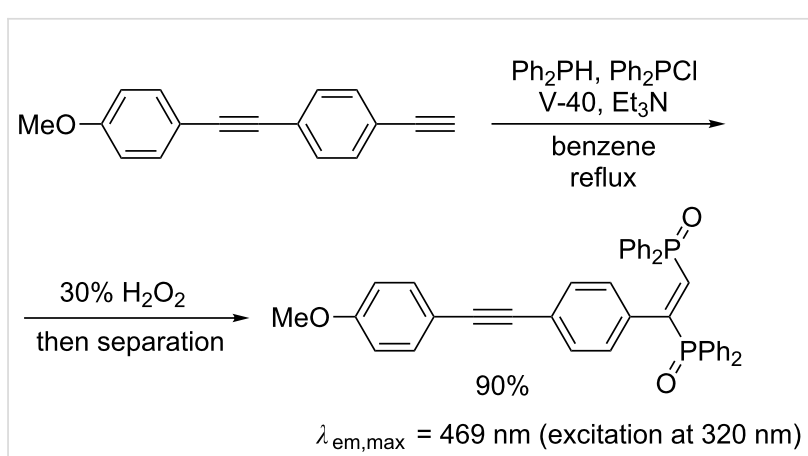

Scheme 8: Radical diphosphination for synthesizing fluorescent material.

Table 2: Photoinduced radical diphosphination of terminal alkynes.

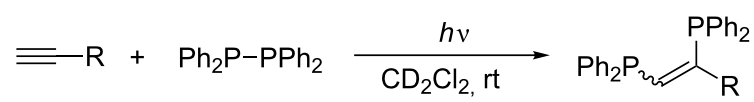

\begin{tabular}{llll}
\hline $\mathrm{R}$ & Time (h) & Yield (\%) & $E / Z$ \\
\hline $\mathrm{CH}_{2} \mathrm{CH}_{2} \mathrm{CHMe}_{2}$ & 39 & 62 & $18: 82$ \\
$\left(\mathrm{CH}_{2}\right)_{3} \mathrm{Cl}$ & 18 & 55 & $42: 58$ \\
$\mathrm{Ph}$ & 1 & 45 & $<1: 99$
\end{tabular}

tion of initially formed $E$ isomers. Ogawa's diphosphination is thus potentially useful for the synthesis of (Z)-1,2-diphosphanyl-1-alkenes, which can serve as bidentate ligands.

Morse developed photoinduced addition of tetrafluorodiphosphine to alkenes and alkynes in the gas phase (Table 3) [31-34]. The addition provides a series of intriguing bidentate phosphine ligands. The addition to alkynes yields 1:1 mixtures of $E / Z$ isomers. Due to the high reactivity of a difluorophosphanyl radical, considerable polymerization takes place unless substrates or olefinic products are reasonably inert.

Yorimitsu and Oshima reported radical addition of a $\mathrm{P}-\mathrm{S}$ bond across alkyne by using diphenyl(organosulfanyl)phosphine (Table 4) [35]. The addition proceeds mainly in an anti fashion to afford the adducts bearing a sulfanyl group at the terminal carbon and a phosphanyl group at the internal carbon. The reaction mechanism is similar to that in Scheme 7 (Scheme 9). The regioselective outcome suggests that the homolytic substitution occurs exclusively at phosphorus, not at sulfur. A sulfanyl radical is liberated to add the terminal carbon of alkyne. To reverse the regioselectivity in radical addition of a $\mathrm{P}-\mathrm{S}$ bond, $S$-thiophosphinyl $O$-ethyl dithiocarbonates were created, although the reversed addition excludes homolytic substitution at phosphorus (Scheme 10) [36]. 
Table 3: Photoinduced radical diphosphination with tetrafluorodiphosphine.

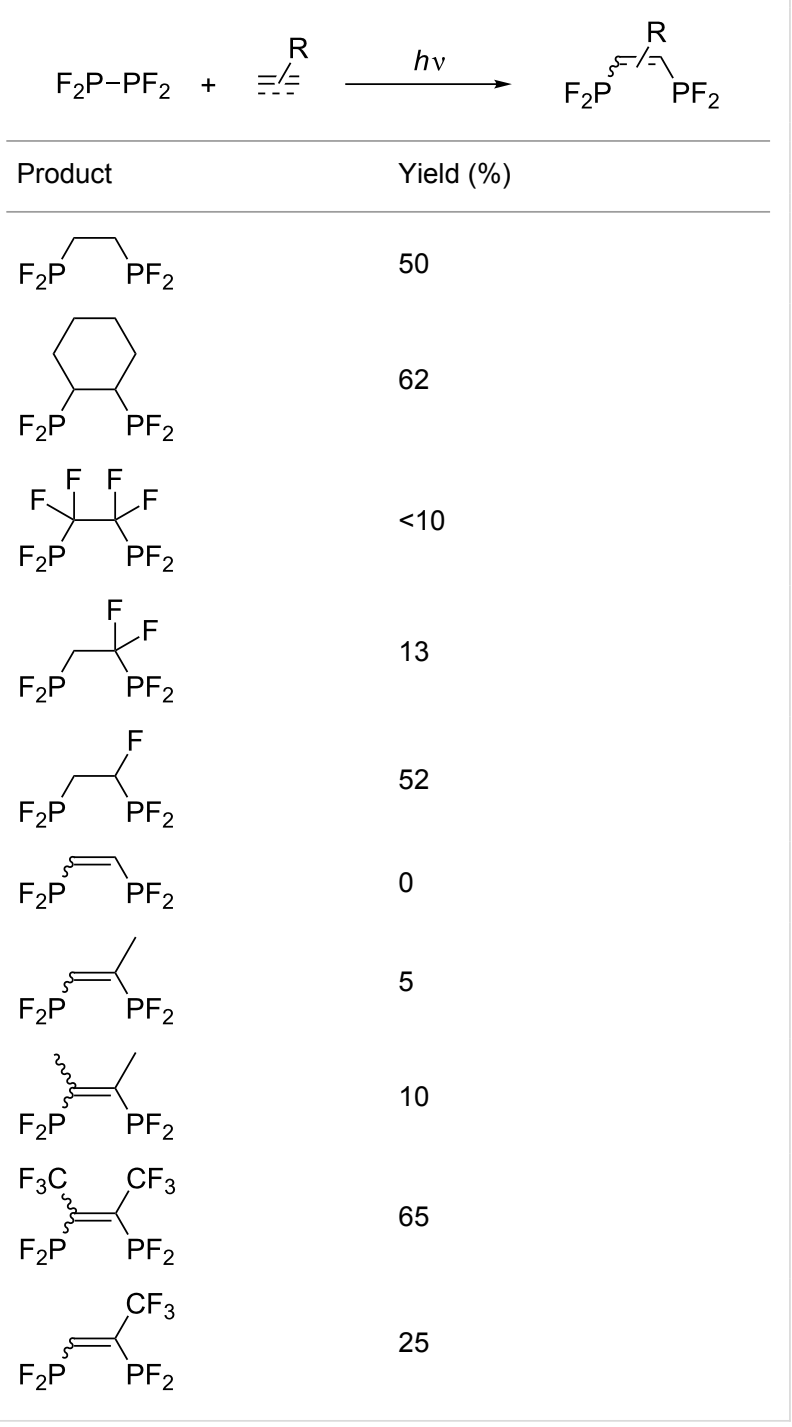

Table 4: Thiophosphination of terminal alkynes.

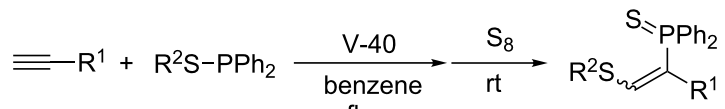

$$
\begin{aligned}
& E / Z=94: 6-84: 16
\end{aligned}
$$

\begin{tabular}{lll}
\hline $\mathrm{R}^{1}$ & $\mathrm{R}^{2}$ & Yield (\%) \\
\hline $\mathrm{C}_{10} \mathrm{H}_{21}$ & $\mathrm{Ph}$ & 75 \\
$c-\mathrm{C}_{6} \mathrm{H}_{11}$ & $\mathrm{Ph}$ & 61 \\
$\mathrm{Ph}$ & $\mathrm{Ph}$ & 83 \\
$\mathrm{C}_{6} \mathrm{H}_{4}-p-\mathrm{OMe}$ & $\mathrm{Ph}$ & 75 \\
$\mathrm{C}_{6} \mathrm{H}_{4}-\mathrm{O}-\mathrm{OMe}$ & $\mathrm{Ph}$ & 85 \\
$\mathrm{C}_{6} \mathrm{H}_{4}-p-\mathrm{COMe}$ & $\mathrm{Ph}$ & 69 \\
$\mathrm{C}_{6} \mathrm{H}_{4}-p-\mathrm{CO}_{2} \mathrm{Me}$ & $\mathrm{Ph}$ & 73 \\
$\mathrm{C}_{6} \mathrm{H}_{4}-p-\mathrm{CF}_{3}$ & $\mathrm{Ph}$ & 69 \\
$\mathrm{C}_{6} \mathrm{H}_{4}-p-\mathrm{NH}_{2}$ & $\mathrm{Ph}$ & 80 \\
$\left(\mathrm{CH}_{2}\right){ }_{3} \mathrm{OH}$ & $\mathrm{Ph}$ & 66 \\
$\mathrm{C}_{6} \mathrm{H}_{4}-p-\mathrm{OMe}$ & $\mathrm{C}_{12} \mathrm{H}_{25}$ & 70 \\
$\mathrm{C}_{10} \mathrm{H}_{21}$ & $\mathrm{C}_{12} \mathrm{H}_{25}$ & 42 \\
$\mathrm{C}_{10} \mathrm{H}_{21}$ & $t-\mathrm{Bu}$ & 51
\end{tabular}

Kawaguchi, Nomoto, and Ogawa seminally studied the photoinduced radical chalcogenophosphination of alkynes and allenes by means of $\mathrm{PhCh}-\mathrm{ChPh} / \mathrm{Ph}_{2} \mathrm{P}-\mathrm{PPh}_{2}$ binary systems $(\mathrm{Ch}=\mathrm{S}$, $\mathrm{Se}, \mathrm{Te}$ ) [30,37-39]. The regioselective outcome of the photoinduced thio- and selenophosphination of terminal alkynes (Table 5) is similar to that of the thermal thiophosphination (Scheme 9). Detailed mechanistic studies revealed that comproportionation between $\mathrm{PhSe}-\mathrm{SePh}$ and $\mathrm{Ph}_{2} \mathrm{P}-\mathrm{PPh}_{2}$ occurs smoothly to generate $\mathrm{PhSe}-\mathrm{PPh}_{2}$ as the actual reactive species. Selenophosphination of terminal allene affords (2-phenylselenyl-2-alkenyl)diphenylphosphine regioselectively (Scheme 11). Notably, the sense of the regioselectivity of

Table 5: Photoinduced thio- and selenophosphination by dichalcogen/ diphosphine binary system.

$$
\begin{aligned}
& \equiv \mathrm{R} \\
& \stackrel{+}{+} \underset{+}{\mathrm{PhCh}-\mathrm{ChPh}} \stackrel{h v(>350 \mathrm{~nm})}{\mathrm{CDCl}_{3}, \mathrm{rt}} \underset{\mathrm{PhCh}_{\mathrm{R}}}{\stackrel{\mathrm{PPh}_{2}}{\longrightarrow}} \\
& \mathrm{Ph}_{2} \mathrm{P}-\mathrm{PPh}_{2} \quad E / Z=94: 6-85: 15
\end{aligned}
$$
fanyl)phosphine.

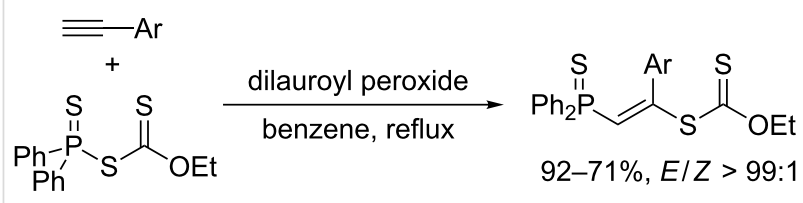

Scheme 10: Thiophosphination with S-thiophosphinyl O-ethyl dithiocarbonate.

\begin{tabular}{lll}
\hline $\mathrm{R}$ & $\mathrm{Ch}$ & Yield (\%) \\
\hline $\mathrm{C}_{6} \mathrm{H}_{13}$ & $\mathrm{~S}$ & 77 \\
$\mathrm{C}_{6} \mathrm{H}_{4}-p$-OMe & $\mathrm{S}$ & 91 \\
1 -cyclohexenyl & $\mathrm{S}$ & 87 \\
$\mathrm{C}_{6} \mathrm{H}_{4}-p-\mathrm{Br}$ & $\mathrm{Se}$ & 96 \\
$\mathrm{C}_{6} \mathrm{H}_{4}-p-\mathrm{OMe}$ & $\mathrm{Se}$ & 78 \\
1 -cyclohexenyl & $\mathrm{Se}$ & 83
\end{tabular}




$$
\begin{aligned}
& { }^{\prime}{ }_{\mathrm{R}}
\end{aligned}
$$

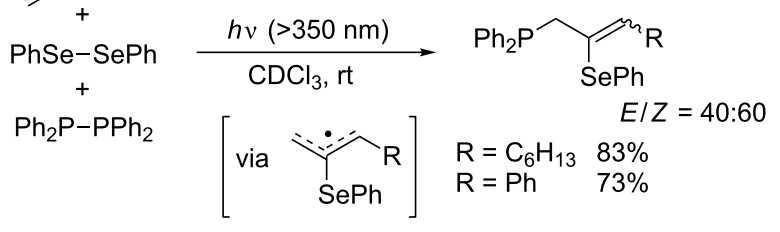

Scheme 11: Photoinduced selenophosphination of allenes.

tellurophosphination by a $\mathrm{PhTe}-\mathrm{TePh} / \mathrm{Ph}_{2} \mathrm{P}-\mathrm{PPh}_{2}$ system is opposite to those of the thio- and selenophosphination (Scheme 12). This reversal indicates that homolytic substitution at tellurium overwhelms that at phosphorus and that a diphenylphosphanyl radical is more reactive than a phenyltelluranyl radical.

$$
\begin{aligned}
& \equiv \mathrm{C}_{6} \mathrm{H}_{4}-p-\mathrm{CF}_{3}
\end{aligned}
$$

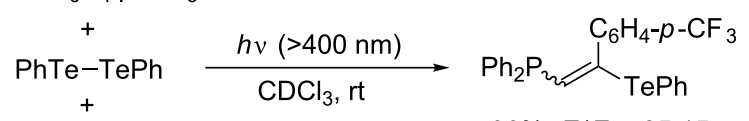

$$
\begin{aligned}
& \mathrm{Ph}_{2} \mathrm{P}-\mathrm{PPh}_{2} \\
& 96 \%, E / Z=85: 15
\end{aligned}
$$

Scheme 12: Photoinduced tellurophosphination.

\section{Substitution of halides $(\mathrm{X})$, carboxys (COOR), or carboxylates (OCOR) with phosphorus}

After scattered research efforts into the uncontrolled radical $\mathrm{C}-\mathrm{H}$ phosphination under harsh reaction conditions [40], Barton elegantly devised radical decarboxylative phosphorylation of carboxylic thiohydroxamic mixed anhydrides (Scheme 13) [41]. Radical addition of a phenylsulfanyl radical to the thiocarbonyl generates the corresponding alkyl radical $\mathrm{R} \cdot$, which undergoes homolytic substitution at the phosphorus of $\mathrm{P}(\mathrm{SPh})_{3}$ to furnish $(\mathrm{PhS})_{2} \mathrm{P}-\mathrm{R}$ as the initial product (Scheme 14). Oxidative addition of the disulfide byproduct to the initial product furnishes a pentavalent phosphorus species that is eventually hydrolyzed to an $S, S$-diphenyl dithiophosphonate upon workup.

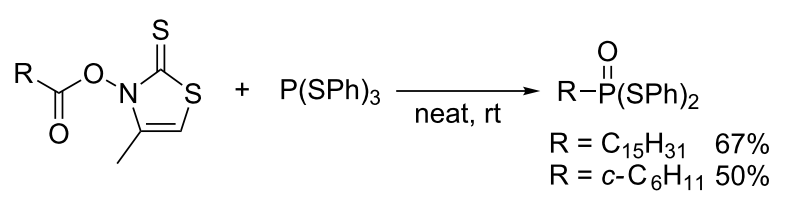

Scheme 13: Decarboxylative phosphorylation of carboxylic acid derivatives.

Barton also reported that white phosphorus reacts with $N$-acyloxythiopyridones, so-called Barton PTOC esters (Scheme 15) [42]. Photolysis of the esters in the presence of

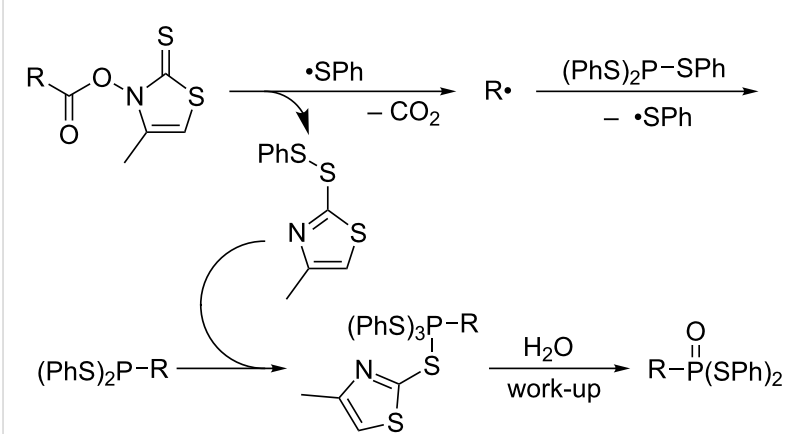

Scheme 14: Plausible mechanism of decarboxylative phosphorylation

white phosphorus followed by oxidation with hydrogen peroxide yields alkylphosphonic acid. The efficient phosphination would stem from the highly strained structure and the weak $\mathrm{P}-\mathrm{P}$ bonds of white phosphorus.

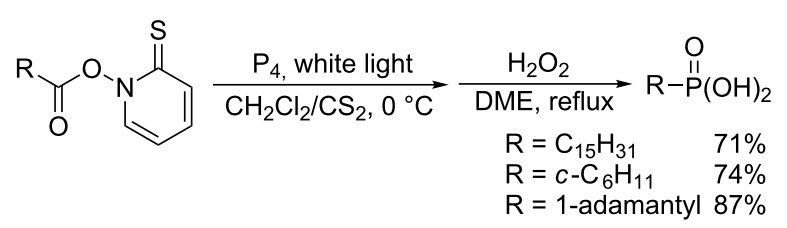

Scheme 15: Radical phosphination of PTOC esters with white phosphorus.

After 13 years of silence, radical substitution reactions of organic halides and related compounds with phosphination agents have now been rapidly developing since 2006 . Yorimitsu and Oshima invented radical phosphination of organic halides with tetraphenyldiphosphine (Table 6) [43].

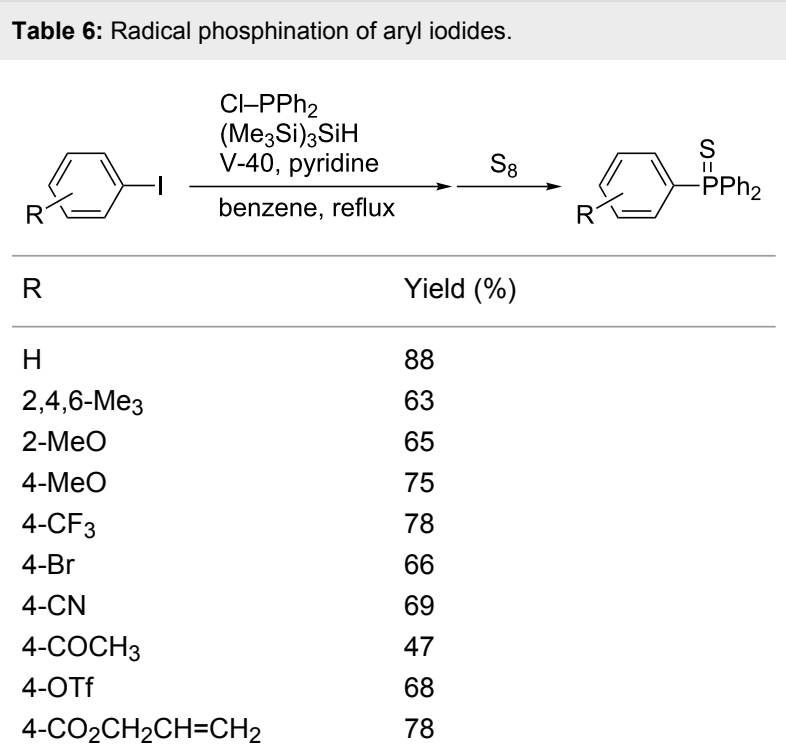


Tetraphenyldiphosphine is generated in situ by radical reduction of chlorodiphenylphosphine with tris(trimethylsilyl)silane followed by condensation of the resulting diphenylphosphine with the remaining chlorophosphine (Scheme 16, equation 1 and 2). An aryl radical reacts with tetraphenyldiphosphine to liberate a diphenylphosphanyl radical, which abstracts hydrogen from tris(trimethylsilyl)silane to sustain the chain propagation (Scheme 16, equation 3-5). The in situ formations of diphenylphosphine and of tetraphenyldiphosphine can exclude the handling of pyrophoric diphenylphosphine and air-sensitive tetraphenyldiphosphine. The user-friendly conditions are also suitable for dicyclohexylphosphination with $\mathrm{ClP}\left(c-\mathrm{C}_{6} \mathrm{H}_{11}\right)_{2}$.

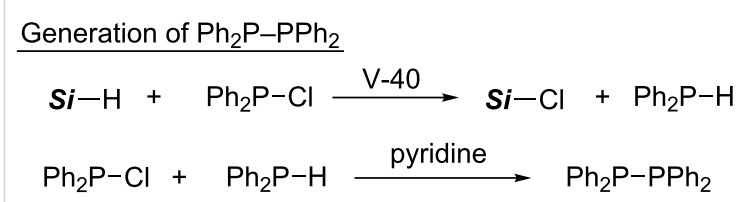

\section{Radical Phosphination with $\mathrm{Ph}_{2} \mathrm{P}-\mathrm{PPh}_{2}$}

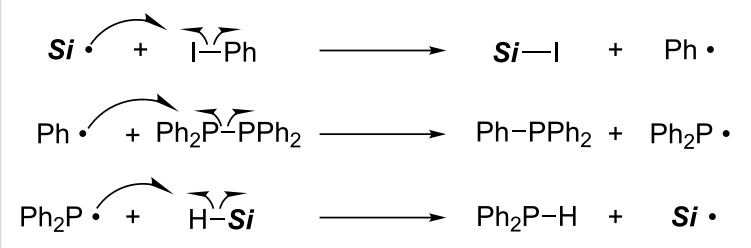

Scheme 16: Plausible mechanism of radical phosphination $(S i=$ $\left.\left(\mathrm{Me}_{3} \mathrm{Si}\right)_{3} \mathrm{Si}\right)$.

Phosphination of alkyl halides as substrates results in unsatisfactory yields. Instead, Barton's alkyl imidazole-1-carbothioates are good substrates for this radical phosphination (Table 7). Conversion of an optically pure cis-carbothioate leads to transaminophosphine of potential use as a ligand (Scheme 17).

Table 7: Radical phosphination of alkyl imidazole-1-carbothioates.

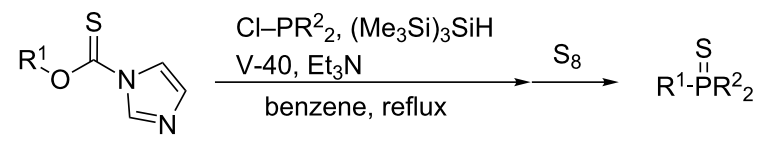

\begin{tabular}{lll}
\hline $\mathrm{R}^{1}$ & $\mathrm{R}^{2}$ & Yield (\%) \\
\hline$c-\mathrm{C}_{6} \mathrm{H}_{11}$ & $\mathrm{Ph}$ & 87 \\
$c-\mathrm{C}_{6} \mathrm{H}_{11}$ & $c-\mathrm{C}_{6} \mathrm{H}_{11}$ & 68 \\
$\mathrm{EtOCOCH}{ }_{2} \mathrm{CH}\left(\mathrm{CH}_{3}\right)$ & $\mathrm{Ph}$ & 89 \\
$3-$ oxacyclopentyl & $\mathrm{Ph}$ & 87 \\
$\mathrm{C}_{6} \mathrm{H}_{13}$ & $\mathrm{Ph}$ & 63
\end{tabular}

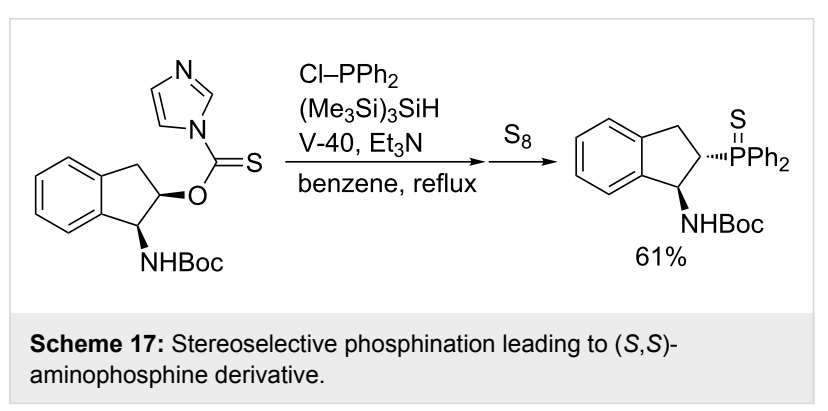

Diphosphine approaches the resulting radical from the opposite side of the NHBoc group to invert the original stereochemistry.

Studer developed in 2007 new elegant reagents $\mathrm{Me}_{3} \mathrm{Sn}-\mathrm{PPh}_{2}$ and $\mathrm{Me}_{3} \mathrm{Si}-\mathrm{PPh}_{2}$ for radical phosphination [44]. The scope of his phosphination with $\mathrm{Me}_{3} \mathrm{Sn}-\mathrm{PPh}_{2}$ is wide as summarized in Table 8. Although the low toxicity of $\mathrm{Me}_{3} \mathrm{Si}-\mathrm{PPh}_{2}$ is advantageous, phosphination with $\mathrm{Me}_{3} \mathrm{Si}-\mathrm{PPh}_{2}$ is limited to alkyl halides or imidazole-1-carbothioate. Density functional theory calculations have clarified the homolytic substitution process is a two-step mechanism via a tetracoordinated phosphorus atom (Figure 1). The spin density in the tetracoordinated phosphorus intermediate is localized mostly on the Sn atom while the remaining spin density is found in the equatorial position of the distorted trigonal prismatic $\mathrm{P}$ atom.

Table 8: Radical phosphination with $\mathrm{Me}_{3} \mathrm{Sn}-\mathrm{PPh}_{2}$

$$
\mathrm{R}-\mathrm{X} \underset{\text { benzene, reflux }}{\stackrel{\mathrm{V}-40, \mathrm{Me}_{3} \mathrm{Sn}-\mathrm{PPh}_{2}}{\longrightarrow}} \stackrel{\mathrm{H}_{2} \mathrm{O}_{2}}{\longrightarrow} \stackrel{\stackrel{\mathrm{O}}{\mathrm{I}}-\mathrm{PPh}_{2}}{\longrightarrow}
$$

\begin{tabular}{ll}
\hline $\mathrm{R}-\mathrm{X}$ & Yield (\%) \\
\hline$p-\mathrm{MeOC}_{6} \mathrm{H}_{4}-\mathrm{I}$ & 73 \\
$p-\mathrm{NCC}_{6} \mathrm{H}_{4}-\mathrm{I}$ & 79 \\
$p-\mathrm{CF}_{3} \mathrm{C}_{6} \mathrm{H}_{4}-\mathrm{I}$ & 75 \\
$p-\mathrm{ClC}_{6} \mathrm{H}_{4}-\mathrm{I}$ & 72 \\
$o-\mathrm{MeOC}_{6} \mathrm{H}_{4}-\mathrm{I}$ & 59 \\
$o-\mathrm{MeO}_{2} \mathrm{CC}_{6} \mathrm{H}_{4}-\mathrm{I}$ & 73 \\
$\mathrm{CH}_{3} \mathrm{CBr}_{\mathrm{C}} \mathrm{CH}_{2}$ & 76 \\
$\mathrm{C}_{5} \mathrm{H}_{11}-\mathrm{I}$ & 79 \\
$c-\mathrm{C}_{6} \mathrm{H}_{11}-\mathrm{I}$ & 94 \\
$\mathrm{C}_{11} \mathrm{H}_{23}-\mathrm{Br}$ & 54 \\
$t-\mathrm{Bu}-\mathrm{Br}$ & 83 \\
$\mathrm{C}_{5} \mathrm{H}_{11}-\mathrm{SePh}$ & 60 \\
$c-\mathrm{C}_{6} \mathrm{H}_{11}-\mathrm{OCS}-1$-imidazole & 57 \\
&
\end{tabular}

The rate constant for phosphination of an aryl radical with $\mathrm{Me}_{3} \mathrm{Sn}-\mathrm{PPh}_{2}$ is calculated to be ca. $9 \times 10^{8} \mathrm{M}^{-1} \mathrm{~s}^{-1}$ by competition kinetics with $\mathrm{Bu}_{3} \mathrm{SnH}$ reduction [45]. This large rate constant allows for stereospecific trapping of axially chiral acyl 


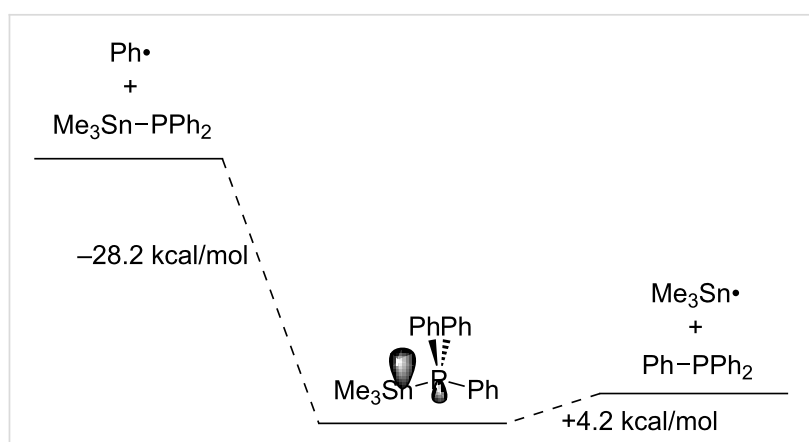

Figure 1: Calculated reaction profile of homolytic substitution between $\mathrm{Ph} \cdot$ and $\mathrm{Me}_{3} \mathrm{Sn}-\mathrm{PPh}_{2}$ at the B2-PLYP-D/TZVVP//PBE-D/TZVP level. Gray lobes indicate major spin densities.

radicals with $\mathrm{Me}_{3} \mathrm{Sn}-\mathrm{PPh}_{2}$ (Scheme 18). Chemodivergent trapping of diastereomers of an $N$-(2-cyclohexenyl)acetanilide derivative is interesting (Scheme 19). One isomer undergoes direct phosphination while the other cyclizes prior to phosphination.

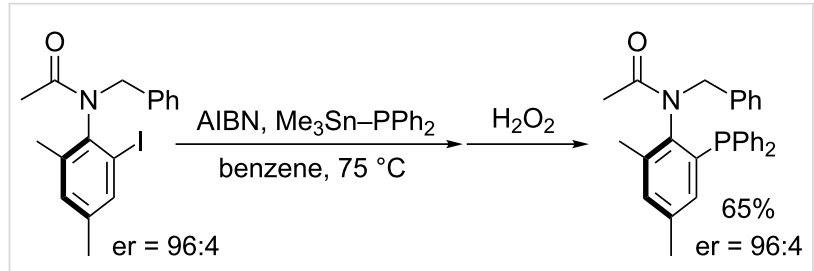

Scheme 18: Phosphination with retention of axial chirality.

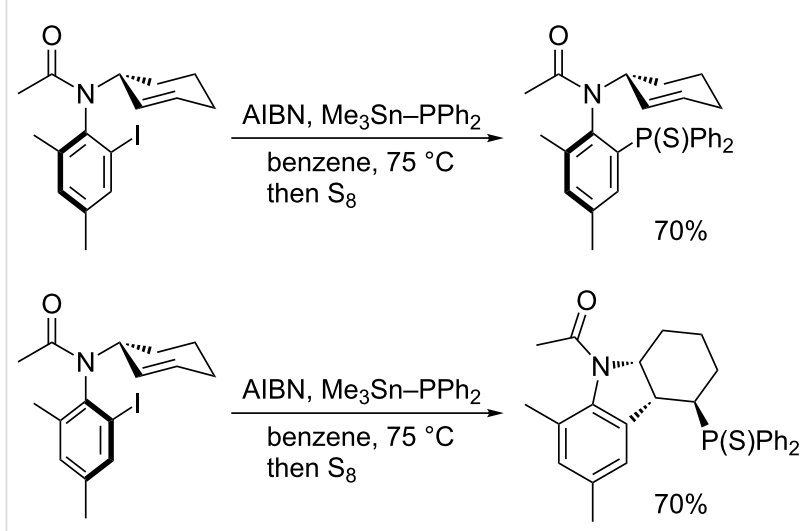

Scheme 19: Chemodivergent phosphination.

Intermolecular phosphinative radical addition of alkyl iodides to activated alkenes proceeds in the presence of $\mathrm{Me}_{3} \mathrm{M}-\mathrm{PPh}_{2}(\mathrm{M}=$ $\mathrm{Sn}, \mathrm{Si}$ ) and V-40 (Table 9) [26]. Secondary and tertiary alkyl iodides participate in the addition reaction while primary alkyl iodide results in direct phosphination prior to the expected addition. Not only acrylate ester but also acrylamide, vinyl sulfone, and acrylonitrile are good radical acceptors in this addition.
Table 9: Phosphinative radical addition of alkyl iodides to activated alkenes.

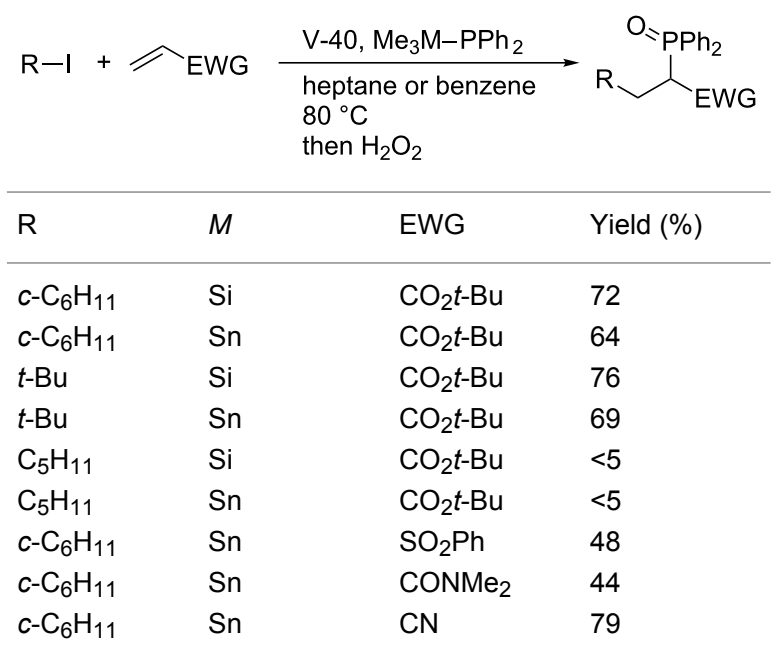

Studer's stannylphosphine technology is reliable enough to be applied to the construction of interesting $\pi$-conjugated frameworks. In collaboration with Yamaguchi, Studer invented a new radical reagent $\left(\mathrm{Me}_{3} \mathrm{Sn}\right)_{2} \mathrm{PPh}$ for the synthesis of highly strained bis(phosphoryl)-bridged biphenyls (Scheme 20) [46]. Subsequently, Liu reported an efficient synthesis of bis(phosphoryl)bridged ladder triphenylene by means of the radical clipping with $\left(\mathrm{Me}_{3} \mathrm{Sn}\right)_{2} \mathrm{PPh}$ (Scheme 21) [47]. In light of the increasing importance of phosphoryl-bridged $\pi$-conjugated skeletons in organic material sciences, $\left(\mathrm{Me}_{3} \mathrm{Sn}\right)_{2} \mathrm{PPh}$ will serve as a key reagent.<smiles>[R]c1cc(Br)c(-c2c(Br)cc([R])cc2Br)c(Br)c1</smiles>

Scheme 20: Bis(phosphoryl)-bridged biphenyls by radical phosphination.

Ogawa developed photoinduced phosphination of perfluoroalkyl iodides with tetraorganodiphosphines (Scheme 22) [48]. Remarkably, the phosphination proceeds quantitatively. The phosphine ligands thus synthesized are fluorophilic. Particu- 


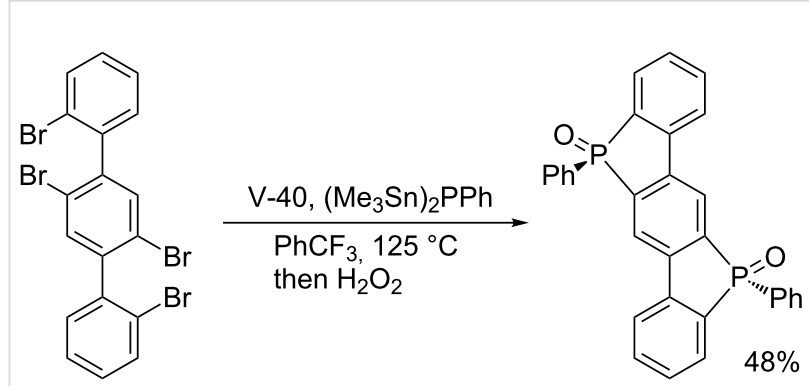

Scheme 21: Bis(phosphoryl)-bridged ladder triphenylene by radical phosphination.

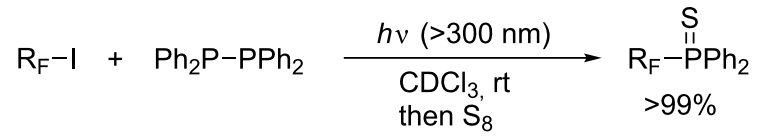

$$
\begin{aligned}
& \mathrm{R}_{\mathrm{F}}=\mathrm{C}_{10} \mathrm{~F}_{21}, \mathrm{C}_{8} \mathrm{~F}_{17}, \mathrm{C}_{6} \mathrm{~F}_{13}, \mathrm{C}_{4} \mathrm{~F}_{9} \text {, } \\
& c-\mathrm{C}_{6} \mathrm{~F}_{11}, \mathrm{iC}_{3} \mathrm{~F}_{7},-\left(\mathrm{CF}_{2}\right)_{6^{-}},-\left(\mathrm{CF}_{2}\right)_{4^{-}}
\end{aligned}
$$

Scheme 22: Photoinduced phosphination of perfluoroalkyl iodides with tetraphenyldiphosphine.

larly, two molecules of perfluorodecyldiphenylphosphine coordinate to palladium dichloride to form a catalytically active palladium complex that is useful for a fluorous/organic biphasic system.

Cummins devised radical phosphination of bromobenzene or bromocyclohexane with white phosphorus by means of a trivalent titanium complex (Scheme 23) [49]. This represents a unique direct method for preparing triorganophosphine without recourse to any trivalent phosphorus sources such as $\mathrm{PCl}_{3}$.

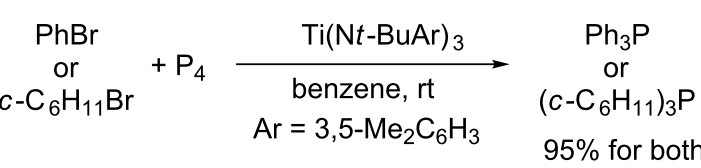

Scheme 23: Ti(III)-mediated radical phosphination of organic bromides with white phosphorus.

\section{Conclusion}

Introduction of a phosphorus atom by a radical process has offered an intriguing tool for the synthesis of organophosphorus compounds. Radical addition of a phosphorus-centered radical has been representative so far. A recent dramatic growth in reports of homolytic substitution at phosphorus in organic synthesis has changed the landscape of radical phosphination. Radical addition that involves homolytic substitution at phos- phorus always culminates in difunctionalization of a multiple bond. Therefore this methodology will find application in the synthesis of complex phosphines including bidentate ones. Radical substitution of halogen in organic halide with phosphorus will be an alternative to classical ionic substitution. Advantageously, it requires neither highly basic conditions nor transition metals. Homolytic substitution at phosphorus is still in its infancy. In light of the rich chemistry of organophosphorus compounds, it will find wider application in organic synthesis in the future.

\section{Acknowledgements}

Preparation of this article and parts of synthetic chemistry in this article were supported by JSPS and MEXT (Grants-in-Aid for Scientific Research, Nos. 24685007, 23655037, 22106523, and 24106721 "Reaction Integration") and by The Uehara Memorial Foundation, NOVARTIS Foundation for the Promotion of Science, Kinki Invention Center, and Takeda Science Foundation. Special thanks are given to those listed as the coauthors in our papers cited herein, particularly to Dr. Akinori Sato, Dr. Azusa Kondoh, and Professor Koichiro Oshima for their invaluable contributions.

\section{References}

1. Organophosphorus Chemistry; Royal Society of Chemistry: Cambridge, U.K.; Vol. 1-40.

2. New Aspects in Phosphorus Chemistry; Springer: Berlin, Germany; Vol. 1-5.

3. Mathey, F., Ed. Science of Synthesis: Houben-Weyl Methods of Molecular Transformation; Thieme: Stuttgart, Germany, 2008; Vol. 42.

4. Murphy, P. J., Ed. Organophosphorus Reagents; Oxford University Press: Oxford, U.K., 2004.

5. Beletskaya, I. P.; Kazankova, M. A. Russ. J. Org. Chem. 2002, 38, 1391-1430. doi:10.1023/A:1022685801622

6. Schwan, A. L. Chem. Soc. Rev. 2004, 33, 218-224. doi:10.1039/b307538a

7. Tappe, F. M. J.; Trepohl, V. T.; Oestreich, M. Synthesis 2010, 3037-3062. doi:10.1055/s-0030-1257960

8. Wicht, D. K.; Glueck, D. S. Hydrophosphination and Related Reactions. In Catalytic Heterofunctionalization; Togni, A.; Grützmacher, H., Eds.; Wiley: Weinheim, Germany, 2001. doi:10.1002/3527600159.ch5

9. Alonso, F.; Beletskaya, I. P.; Yus, M. Chem. Rev. 2004, 104 3079-3159. doi:10.1021/cr0201068

10. Tanaka, M. Top. Curr. Chem. 2004, 232, 25-54. doi:10.1007/b13778

11. Delacroix, O.; Gaumont, A. C. Curr. Org. Chem. 2005, 9, 1851-1882. doi:10.2174/138527205774913079

12. Baralle, A.; Baroudi, A.; Daniel, M.; Fensterbank, L.; Goddard, J.-P.; Lacôte, E.; Larraufie, M.-H.; Maestri, G.; Malacria, M.; Olivier, C. Main-Group Elements in Radical Chemistry. In Encyclopedia of Radicals in Chemistry, Biology and Materials; Wiley: Weinheim, Germany, 2012; Vol. 2, Chapter 28. doi:10.1002/9781119953678.rad023

13. Leca, D.; Fensterbank, L.; Lacôte, E.; Malacria, M. Chem. Soc. Rev. 2005, 34, 858-865. doi:10.1039/b500511f

14. Walling, C.; Pearson, M. S. Top. Phosphorus Chem. 1966, 3, 1-56. 
15. Stacy, F. W.; Harris, J. F. Org. React. 1963, 13, 150-376.

16. Kyne, S. H.; Schiesser, C. H. Intramolecular Homolytic Substitution in Synthesis. In Encyclopedia of Radicals in Chemistry, Biology and Materials; Chatgilialoglu, C.; Studer, A., Eds.; Wiley: Weinheim, Germany, 2012; Vol. 2, Chapter 24. doi:10.1002/9781119953678.rad018

17. Schiesser, C. H.; Wild, L. M. Tetrahedron 1996, 52, 13265-13314. doi:10.1016/0040-4020(96)00809-5

18. Crich, D. Helv. Chim. Acta 2006, 89, 2167-2182. doi:10.1002/hlca.200690204

19. Walton, J. C. Acc. Chem. Res. 1998, 31, 99-107. doi:10.1021/ar970259v

20. Bentrude, W. G. Acc. Chem. Res. 1982, 15, 117-125. doi:10.1021/ar00076a004

21. Bentrude, W. G. Chapter 22: Phosphorus Radicals. In Free Radicals; Kochi, J. K., Ed.; Wiley: Weinheim, Germany, 1973; Vol. 2.

22. Schumann, H.; Jutzi, P.; Schmidt, M. Angew. Chem., Int. Ed. Engl. 1965, 4, 869. doi:10.1002/anie.196508692

23. Schumann, H. Angew. Chem., Int. Ed. Engl. 1969, 8, 937-950. doi:10.1002/anie.196909371

24. Mitchell, T. N.; Belt, H.-J. J. Organomet. Chem. 1988, 345, C28-C30. doi:10.1016/0022-328X(88)80105-0

25. Mitchell, T. N.; Belt, H.-J. J. Organomet. Chem. 1990, 386, 167-176. doi:10.1016/0022-328X(90)85241-P

26. Lamas, M.-C.; Studer, A. Org. Lett. 2011, 13, 2236-2239. doi:10.1021/ol200483p

27. Tzschach, A.; Baensch, S. J. Prakt. Chem. 1971, 313, 254-258. doi:10.1002/prac.19713130209

28. Sato, A.; Yorimitsu, A.; Oshima, K. Angew. Chem., Int. Ed. 2005, 44, 1694-1696. doi:10.1002/anie.200462603

29. Kawaguchi, S.-i.; Nagata, S.; Shirai, T.; Tsuchii, K.; Nomoto, A.; Ogawa, A. Tetrahedron Lett. 2006, 47, 3919-3922. doi:10.1016/j.tetlet.2006.03.165

30. Kawaguchi, S.-i.; Ogawa, A. J. Synth. Org. Chem., Jpn. 2010, 68, 705-717. doi:10.5059/yukigoseikyokaishi.68.705

31. Morse, K. W.; Morse, J. G. J. Am. Chem. Soc. 1973, 95, 8469-8470. doi:10.1021/ja00806a057

32. Morse, J. G.; Morse, K. W. Inorg. Chem. 1975, 14, 565-569. doi:10.1021/ic50145a024

33. Glanville, W. K.; Morse, K. W.; Morse, J. G. J. Fluorine Chem. 1976, 7, 153-158. doi:10.1016/S0022-1139(00)83992-5

34. Morse, J. G.; Mielcarek, J. J. J. Fluorine Chem. 1988, 40, 41-49. doi:10.1016/S0022-1139(00)81060-X

35. Wada, T.; Kondoh, A.; Yorimitsu, A.; Oshima, K. Org. Lett. 2008, 10 , 1155-1157. doi:10.1021/ol800059n

36. Sato, A.; Yorimitsu, A.; Oshima, K. Tetrahedron 2009, 65, 1553-1558. doi:10.1016/j.tet.2008.12.071

37. Shirai, T.; Kawaguchi, S.-i.; Nomoto, A.; Ogawa, A. Tetrahedron Lett. 2008, 49, 4043-4046. doi:10.1016/j.tetlet.2008.04.068

38. Kawaguchi, S.-i.; Shirai, T.; Ohe, T.; Nomoto, A.; Sonoda, M.; Ogawa, A. J. Org. Chem. 2009, 74, 1751-1754. doi:10.1021/j08020067

39. Kawaguchi, S.-i.; Ohe, T.; Shirai, T.; Nomoto, A.; Sonoda, M.; Ogawa, A. Organometallics 2010, 29, 312-316. doi:10.1021/om9008982

40. Sakurai, H.; Okamoto, Y. J. Synth. Org. Chem., Jpn. 1976, 34, 203-214.

41. Barton, D. H. R.; Bridon, D.; Zard, S. Z. Tetrahedron Lett. 1986, 27 , 4309-4312. doi:10.1016/S0040-4039(00)94261-8
42. Barton, D. H. R.; Zhu, J. J. Am. Chem. Soc. 1993, 115, 2071-2072. doi:10.1021/ja00058a082

43. Sato, A.; Yorimitsu, A.; Oshima, K. J. Am. Chem. Soc. 2006, 128 , 4240-4241. doi:10.1021/ja058783h

44. Vaillard, S. E.; Mück-Lichtenfeld, C.; Grimme, S.; Studer, A. Angew. Chem., Int. Ed. 2007, 46, 6533-6536. doi:10.1002/anie.200701650

45. Bruch, A.; Ambrosius, A.; Fröhlich, R.; Studer, A.; Guthrie, D. B.; Zhang, H.; Curran, D. P. J. Am. Chem. Soc. 2010, 132, 11452-11454. doi:10.1021/ja105070k

46. Bruch, A.; Fukazawa, A.; Yamaguchi, E.; Yamaguchi, S.; Studer, A. Angew. Chem., Int. Ed. 2011, 50, 12094-12098. doi:10.1002/anie.201104114

47. Hanifi, D.; Pun, A.; Liu, Y. Chem.-Asian J. 2012, 7, 2615-2620. doi:10.1002/asia.201200631

48. Kawaguchi, S.-i.; Minamida, Y.; Ohe, T.; Nomoto, A.; Sonoda, M.; Ogawa, A. Angew. Chem., Int. Ed. 2013, 52, 1748-1752. doi:10.1002/anie.201207383

49. Cossairt, B. M.; Cummins, C. C. New J. Chem. 2010, 34, 1533-1536. doi:10.1039/c0nj00124d

\section{License and Terms}

This is an Open Access article under the terms of the Creative Commons Attribution License (http://creativecommons.org/licenses/by/2.0), which permits unrestricted use, distribution, and reproduction in any medium, provided the original work is properly cited.

The license is subject to the Beilstein Journal of Organic Chemistry terms and conditions:

(http://www.beilstein-journals.org/bjoc)

The definitive version of this article is the electronic one which can be found at: doi:10.3762/bjoc. 9.143 